\title{
Advancement in the child attachment interview and the child and adolescent reflective functioning scale using a PDM-2 framework: case reports
}

\author{
Fabiola Bizzi, ${ }^{1}$ Francesca Locati, ${ }^{2}$ Laura Parolin, ${ }^{2}$ Shmueli Goetz Yael, ${ }^{3}$ Emanuela Brusadelli ${ }^{4}$ \\ ${ }^{1}$ Department of Educational Sciences, University of Genoa, Italy; ${ }^{2}$ Department of Psychology, University of Milano-Bicocca, Italy; \\ ${ }^{3}$ Anna Freud Centre, London, United Kingdom; ${ }^{4}$ School of Psychology, University of Wollongong, Australia
}

\begin{abstract}
The Child Attachment Interview (CAI) is a well-established semi-structured interview, widely used to identify attachment representations in middle childhood and adolescence. The application of the Child and Adolescent Reflective Functioning Scale (CRFS) to CAI narratives allows for an assessment of child mentalization, considered a strong predictor of attachment security. The $2^{\text {nd }}$ edition of the Psychodynamic Diagnostic Manual (PDM-2) includes CAI and CRFS as valid and reliable assessment measures in order to assess the dominion of the Mental Functioning axis. The aim of the present paper is to investigate the informative power of CAI and CRFS for the overall understanding of mental functioning and personality in a PDM-2 framework. The present report includes the discussion of two clinical cases of school-aged children in applying the Psychodiagnostic Chart-Second Edition (PDC-2) to

Correspondence: Emanuela Brusadelli, School of Psychology, University of Wollongong, Australia.

E-mail: emanuela@uow.edu.au

Citation: Bizzi, F., Locati, F., Parolin, L., Yael, S. G., \& Brusadelli, E. (2022). Advancement in the child attachment interview and the child and adolescent reflective functioning scale using a PDM-2 framework: case reports. Research in Psychotherapy: Psychopathology, Process and Outcome, 25(1), 57-71. doi: 10.4081/ripppo.2022.586

Contributions: FB, FL and EB contributed equally to the manuscript; FB, EB and FL contributed to the study conception and design. Material preparation and data collection were performed by FB. The first draft of the manuscript was written by FB, FL, EB, and YSG commented on previous versions of the manuscript. All authors read and approved the final manuscript. English has been

the CAI transcript. The first case concerns a young male, aged 10, suffering from Oppositional-Provocative Disorder (externalizing disorder), while the second case concerns a young female, aged 15, suffering from Somatic Symptoms Disorder (internalizing disorder). PDC-2 for children and adolescents was used. Data from the scoring of CAI and CRFS were combined with a systematic evaluation of the qualitative contents emerging from CAI transcripts. A detailed analysis suggests that both the CAI and CRFS are useful attachment-oriented measures, able to explore child's mental states, and together with the application of PDC-2 they provide an essential contribution in the understanding of developmental psychopathology. Implications of this innovative approach for clinical assessment, treatment design, and interventions are further discussed.
\end{abstract} revised by the author of native English (YSG).

Conflict of interest: the authors declare no potential conflict of interest.

Ethical approval and consent to participate: all procedures were in accordance with the ethical standards of the institutional research committee, the international standards, and with the 1964 Helsinki Declaration and its later amendments. Informed consent was obtained from the individual participants included in the study (children and their parents).

Availability of data and material: the data that support the findings of this study are available on request from the corresponding author.

Received for publication: 2 July 2021.

Revision received: 3 February 2022.

Accepted for publication: 11 February 2022.

This work is licensed under a Creative Commons Attribution NonCommercial 4.0 License (CC BY-NC 4.0).

${ }^{\circ}$ Copyright: the Author(s), 2022

Licensee PAGEPress, Italy

Research in Psychotherapy:

Psychopathology, Process and Outcome 2022; 25:57-71

doi:10.4081/ripppo.2022.586
Key words: Child attachment interview; child and adolescent reflective functioning scale; Psychodynamic Diagnostic Manual; developmental psychopathology; case formulation.

\section{Introduction}

Attachment representations were defined as 'attachment working models' by Bowlby (Bowlby, 1980; Bretherton, 1985), indicating the consolidation of the expectations about self, physical and social environment, and close relationships derived from a secure base experience in infancy, that are initially sensorimotor representations (Crowell et al., 2002). During middle childhood and early adolescence, attachment representations evolve, becoming more elaborate and organized in relation to different factors, as the emotional and cognitive changes, the modification of the relationship with the caregiver, and the goal of these representations (Bosmans \& Kerns, 2015). Although it is important to investigate these complex changes, little is known about this topic in middle 
childhood and early adolescence compared to the extensive literature for infancy or adulthood (Bosmans \& Kerns, 2015; Carr, 2017).

Several approaches exist to assess school-aged children's attachment representations, and the more popular are: the narrative story stem technique that are often referred for the youngest to as 'doll play' procedures (e.g., the MacArthur Story Stem Battery, MCAST; Emde et al., 2003); the child's response to ambiguous pictures evoking attachment stressful situations (e.g. the Separation Anxiety Test, SAT; Klagsbrun \& Bowlby, 1976); the interview techniques based on the Adult Attachment Interview (AAI; George et al., 1985) principles (e.g., the Child Attachment Interview, CAI; Shmueli-Goetz et al., 2008, Friends and Family Interview, FFI; Steele \& Steele, 2005) that seek to assess children's perceptions of their attachment figures' current availability. The differences between these measurement approaches make it difficult to compare findings across studies. However, the CAI is considered a goal standard instrument to investigate children's representations of their attachment relationships in scholar-aged (Jewell et al., 2019). On the other hand it is convergent from other tools being an age-specific tool focused on current rather than past relationships with attachment figures, able to capture specific patterns of attachment, as disorganization. On the other hand, it is different since it relies on nonverbal as well as verbal communication in the analysis of narratives and elicits separate representation of attachment figures in coding criteria. In detail, the CAI is a semi-structured interview for children and adolescents, from 8 to 17 years old. Its development was informed by the Adult Attachment Interview (AAI; George et al., 1985) which focuses on discourse analysis, the Strange Situation Procedure (SSP; Ainsworth et al., 1978) which focuses on meaningful behaviours in context, and Luborsky and Crits-Christoph's (1990) system of partitioning narratives into discrete relationship episodes. Through the integration of behavioral and representational approaches, the CAI demonstrates that similarly to adults, children can respond to direct questions concerning attachment-related experiences. Moreover, individual differences in children's responses can be meaningfully analysed, revealing the internal representations of attachment (Shmueli-Goetz et al., 2008).

A growing body of research - specifically, cross-cultural studies - has been conducted using the CAI in both nonclinical and clinical populations (Privizzini, 2017), showing that insecure attachment in general (connoted by experiences with inconsistent parental responses to attachment bids), and disorganized attachment specifically (connoted by the exposure to highly frightening experiences within the attachment relationship), are associated with increased risk of both externalizing and internalizing problems in school-aged children (Madigan et al., 2016). This has been found using the CAI with heterogeneous clinical samples in middle childhood (e.g. Hart et al.,
2017; Jardin et al., 2017), including children with specific clinical conditions, such as depressive symptoms and shyness accompanied by parental reports of social anxiety, attention deficit, and thought problems (Borelli et al., 2010), Attention Deficit Hyperactivity Disorder (Rasmussen et al., 2019), Disruptive Behavior Disorders and Somatic Symptoms Disorders (Bizzi et al., 2015, 2018, $2019,2021 b)$. The use of the CAI has been further extended for assessing attachment status in adolescence. Venta and colleagues (2014a) demonstrated that CAI is a psychometrically strong instrument for assessing attachment representations not only in middle childhood, but also in adolescents ranging in age from 12 to 17, including different clinical categories such as Major Depressive Disorder, Obsessive-Compulsive Disorder, Oppositional Defiant Disorder (Venta et al., 2014a), Obese adolescent females (Holland et al., 2012), adolescents with self-harm and suicide-related thoughts and behaviours (Glazebrook et al., 2015; Venta \& Sharp, 2014b).

As a further extension to the CAI, the Child and Adolescent Reflective Functioning Scale, (CRFS: Ensink et al., 2013) was subsequently developed as a way of measuring the capacity of children to mentalize. Mentalization (or mentalizing capacity) refers to the ability to hold others' minds in mind, interpreting behaviours of the self and others in terms of feelings, intentions, beliefs, and desires (Fonagy et al., 2002; Fonagy \& Target, 1997). It is a developmentally acquired capacity that originates in the context of attachment relationships, where a secure base provides a necessary precondition for mentalizing to emerge (Fonagy \& Target, 2006; Fonagy et al., 2007; Shai $\&$ Belsky, 2017). Together with attachment representations, it represents a critical predictor of social and emotional development in childhood and adolescence (Fonagy \& Luyten, 2016; Luyten \& Fonagy, 2018; Luyten et al, 2017, 2020).

Recent advances of mentalization theory (Vrouva et al., 2012) have conceptualized several processes of mentalization, including one more automatic and implicit, that is more reflective and non-verbal, and the other more controlled and explicit, that requires more cognitive effort when decoding mental states. Consistent with this distinction, different approaches have been employed to assess the capacity to mentalize in school-aged children. For instance, the Reading the Mind in the Eyes Test (RMET; Baron-Cohen et al., 2001) requiring the recognition of the mental state in the eyes before any selection of the verbal descriptor, has been used to operationalize implicit mentalization, while assessments of explicit mentalization focus on scoring the content of transcribed open-ended interview questions (e.g., Child and Adolescent Reflective Functioning Scale, CRFS; Ensink, 2013; Affect Task, AT; Fonagy et al., 2000), as well as more story-based vignettes (e.g., Mentalizing Stories for Adolescents, MSA; Vrouva $\&$ Fonagy, 2009). Despite the explicit mentalization assessments requires more significant language ability, the 
CRFS is the only tool that permits the assessment of multiple dimensions of mentalization operationalized as Reflective Functioning (RF; Fonagy et al., 1991), including a self, other and general focused perspective (Vrouva et al., 2012). Studies with CRFS include clinical and community groups, specifically youth with histories of intrafamilial or extrafamilial sexual abuses (Ensik et al., 2015, 2016, 2017; Tessier et al., 2016), youth with emotionalbehavioral problems (Bizzi et al., 2019, 2021a), adolescents with borderline personality traits (Sharp \& Rossouw, 2019; Vanwoerden et al., 2019) and Type I Diabetes patients (Costa-Cordella et al., 2020), showing that lower capacities for mentalization are linked with these clinical conditions.

Both the CAI and CRFS have recently been included among the instruments recommended by the Psychodynamic Diagnostic Manual (2nd ed.; PDM-2; Lingiardi \& McWilliams, 2017) for the assessment of attachment representations and mentalization respectively. The PDM-2 is the most sophisticated diagnostic system, which combines nomothetic and idiographic knowledge in a contemporary psychoanalytic perspective (Kernberg, 2018). Thanks to its person-centered perspective and its multidimensional approach, it is able to capture the overall functioning of patients in different age groups, providing useful indications on how to assess each of the functions and how to shape psychotherapeutic interventions (Lingiardi \& McWilliams, 2018). Patients are grouped by age from Infancy and Early Childhood (0-3 years), Childhood (4-11 years), and Adolescence (12-18 years). In 2020, a reviewed advanced version of these sections of the manual has been published (Lingiardi et al., 2020). For this paper, only the Childhood and Adolescence sections are going to be explored. These sections share a similar structure (analogous to that for adults), that allows retracing the 'developmental path of emerging pathological manifestations in the context of growth and maturation' ( $p$. 466, Lingiardi \& McWilliams, 2017).

The childhood section is composed of Profile of Mental Functioning for Children (MC-Axis), Emerging Personality Patterns and Difficulties in Childhood (PC-Axis), Child Symptom Patterns (SC-Axis). The MCAxis contains the description of eleven basic mental functions, together with guidelines on the expected developmental stage based on age. The MC-Axis provides essential information on self-and emotion regulation, mentalization, capacity for relationships and identity development, self-esteem, impulse control, defensive functioning, resiliency, self-observing capacity, and internal standards. Because children's personalities are evolving, the PC-Axis comes as a 2 nd component to be investigated, and provides information on 'emerging' personality patterns, indicating the specific way a young person engages with others and copes with external requests, considering both their strengths and vulnerabilities. Finally, the SC-Axis includes the description of symptom patterns in a developmental, dynamic context, with a strong multifactor orientation, a connection with categorical diagnostic systems, and a focus on the child's subjective experience. For MC and PC Axes, the PDM-2 provides a list of the most relevant assessment tools available to assess each of the functions considered, that can help the clinician in the complex challenge to create a child's psychodynamic diagnostic profile (Lingiardi \& McWilliams, 2017). Currently, PDM-2 proposed CRFS on CAI as a measure useful to evaluate the Capacity for Mentalization and Reflective Functioning (MC Axis) and it quoted CAI in the bibliography for Capacity for Relationships and Intimacy (MC Axis).

For adolescence, the same order of the Axes is maintained. In addition to the eleven functions explored in the MC-Axis of the Childhood section, the Profile of Mental Functioning for Adolescents (MA-Axis) also includes twelve functions related to the capacity for meaning and purpose (i.e. the individual's ability to construct a personal narrative that gives coherence a meaning to personal choice), which are strictly related to identity construction and moral development in this stage of life. Personality (PA-Axis) requires high attention in adolescence. Indeed, it changes throughout the life course, and in this stage of life, it is possible to evaluate the emerging personality style resulting from the development of personality patterns formed from childhood. In some adolescents, these relatively stable emerging personality style features can show patterns of personality pathology that are reported to closely resemble adult personality pathology with long-term negative outcomes (Kasen et al., 2007). For this reason, its understanding is essential for effective psychotherapeutic treatment planning (Lingiardi \& McWilliams, 2017). To provide an overall understanding of adolescent's personality, the PA-Axis contains the evaluation of the level of personality organization, together with a section on Emerging Personality Syndromes/Styles. As described before, also for adolescents the last Axis is on Subjective Experience of (Adolescent) Symptom Patterns (SA-Axis). Similarly, to the Childhood Section, different tools are recommended for assessing the different functions in adolescence of both MA and PA Axes. However, the CAI and CRFS are not currently included among them. One of the principal PDM-2 assessment tools is the Psychodiagnostic Chart-Second Edition (PDC-2; Gordon \& Bornstein, 2015), which addresses PDM-2's main constructs. The PDC-2 can be effectively used for diagnostic formulations, creating a bridge to compare different diagnostic formulation systems for the identification of treatment targets, and outcomes evaluation (Gordon \& Bornstein, 2018; Malone et al., 2018).

The present study aimed to compare and combine different perspectives, i.e., the attachment and the mentalization one to PDM-2 approach in order to develop a complex view on clinical cases (Salcuni et al., 2014; Tanzilli et al., 2021). More specifically, it focuses on developmental psychopathology, which requires a specific 
approach to catch the complexity of young individuals, different in childhood and in adolescence. This perspective, based on typical and atypical development (Sroufe, 1990), reveals an approach to nosography characterized by a continuation from health to severe pathology and differentiated in developmental stages, consistently with PDM-2. Adopting different approaches and applying them in concert could help clinicians to identify a range of difficulties and struggles, leading to more specific and thus attuned intervention and/or treatment. The combined use of these measures may also contribute to the dialogue between professionals from different theoretical backgrounds, all with the aim of gaining a greater understanding of children's functioning and adaptation (Patriarca et al., 2020).

In this direction, it is also interesting to investigate the informative power derived from the application of the PDM-2 framework on CAIs, together with the use of the CRFS. Indeed, the hypothesis is that CAI is a powerful tool that, together with CRFS, can be used not only for the two domains as indicated in the PDM-2 but to collect information on the overall psychological functioning of children and adolescents. Through the integration of behavioral and representational approaches, the CAI demonstrates that individual differences in children's responses concerning attachment-related experiences can be meaningfully analysed, revealing the internal representations of attachment (Shmueli-Goetz et al., 2008). The quality of these representations are also linked to the general psychological functioning of school-aged children with a reciprocal influence that we believe can be detected by the application of the PDC on the CAI. To reach this goal, the PDC-2 was applied to CAI transcripts, and all the pieces of information derived from these three measures were combined to enhance the understanding of both children and adolescents. Precedence for taking this approach comes from a study demonstrating how the PDC- 2 can be applied to clinical transcripts of AAI (to enhance and strengthen the assessment of adult functioning and psychopathology; Patriarca et al., 2020). The question arises as to whether a similar approach might be fruitful in assessing children and adolescents. To the best of our knowledge, no studies have been yet conducted on the application of the PDC-2 to CAI transcripts of youths. Similarly, the PDM suggests using CRFS to evaluate children' mentalizing domain, inferring the PDC-2 scoring from that, but no research has yet investigated the relationship between these two instruments.

Adopting a case study approach, the goal of this research is, therefore, to evaluate whether combining categorical and dimensional analyses of CAI and CRFS with a systematic evaluation of the qualitative contents emerging from CAI transcripts, using the PDC-2, has added value. We hypothesized that the integration of the two 'systems' may enrich our understanding of youth in middle childhood and adolescence, providing more sophisti- cated information for diagnostic formulation and treatment planning.

\section{Methods}

\section{Participants}

Two clinical cases (one for childhood and one for adolescence, respectively) were selected randomly from a large research sample of patients recruited for a project undertaken by the first author at the Department of Educational Sciences.

\section{Case 1 - Childhood: Luca}

Luca is a 10 -year-old Italian boy who was referred to a paediatric clinical centre because of recurring behaviour, attention, and school problems reported by his teachers and parents. Luca is an only child and lives with both parents, who work as blue-collar workers. Luca had a normal development and very vibrant and opposite temperament. He was described by his parents as a child with a lively intelligence and difficulty following instructions and rules; he often assumed provocative behaviour in the family and showed low tolerance to frustrations. Regarding school attendance, he had no learning or socializing difficulties. Luca felt that his negative behaviour was rejected by his parents, but, at the same time, he lived the degree of alarm that caused them, as a possibility of greater centrality in the family drawing their attention.

At the paediatric clinical centre Gaslini Institute of Genoa (Italy), he received by two experts of mental health a diagnosis of Oppositional-Provocative Disorder that was assessed through several clinical interviews and measures (i.e., Wechsler Intelligence Scale for Children-IV (WISCIV; Weschler, 2003), Family Drawing Test (Corman, 1967), Child Behavior Checklist (CBCL 6-18; Achenbach $\&$ Rescorla, 2001) testing cognitive and emotional functioning. In this circumstance, clinical observation revealed a lower threshold of emotional activation than normal, which would favour impetuous responses even in quiet situations. Luca's cognitive abilities were tested with the WISC-IV (Weschler, 2003), detecting a disharmonious cognitive profile (IQ $=120$ ) with vulnerabilities in Processing Speed Index (a measure of mental speed) and in Working Memory Index (a measure of ability to hold verbal information in short-term memory and to manipulate that information) due to cognitive difficulties such as attention and impulsivity. In contrast, the Verbal Competence Index (measuring the ability to understand, learn and retain verbal information, and to use language to solve novel problems) and the Perceptual Reasoning Index (measuring the ability to understand visual information and to solve novel abstract visual problems) was highly preserved. Regarding emotional abilities, Luca completed the Family Drawing Test (Corman, 1967) showing difficulties in the management of aggressivity (as evidenced 
by marked and energetic stroke at graphic level). Instead, the formal level indicates a good degree of closeness between the components. Luca designed a family composed of a father, a child, and a mother, in which the child is little graphically connoted compared to the parents. The investigation revealed the identification and recognition of the 'naughty' child expressing a sense of self-organized around negative patterns, with the desire to take a positive role. In addition, Luca's parents completed the CBCL 618 (Achenbach \& Rescorla, 2001), a parent-report questionnaire used to assess emotional and behavioral problems in children aged 8-16, that revealed externalizing problems with attention and aggressive problems (Externalizing problems $\mathrm{T}=70$; Aggressive behaviour $\mathrm{T}=70$ ).

\section{Case 2 - Adolescence: Anna}

Anna is a 15-year-old Italian girl who was referred to a paediatric clinical centre because she suffers from somatic symptoms (widespread pain). Anna is the second of two siblings. Both parents work as hospital workers. She grew up in an educated and strict Catholic family in which parents had high school expectations. She achieved good academic results at elementary and middle schools with a significant investment in school (perfectionist traits). Then, due to the worsening of her clinical conditions, school attendance has been discontinued. She passed her eighth-grade exam supported by a private teacher at home (parents were not favourable of choosing a home-school) and enrolled in a language high school following parents' advice. However, at the time of the assessment, she dropped out of school showing total rejection.

Anna had a history of hospitalizations from the very first age (information accurately reported by the father). Since the age of 11, she has suffered from a tension headache not responding to drug therapy. For eight months she complained about abdominal and articular pain that sometimes prevented her from walking and kept the body erect. She also referred to recent weight loss. At the paediatric clinical centre Gaslini Institute of Genoa (Italy), she received by two experts of mental health a diagnosis of Somatic Symptom Disorder following a diagnostic assessment through several clinical interviews and measures (i.e., Wechsler Intelligence Scale for Children-IV (WISC-IV; Weschler, 2003), Multidimensional Anxiety Scale for Children (MASC; March et al., 1997), Child Behavior Checklist (CBCL 6-18; Achenbach \& Rescorla, 2001) testing her developmental history and functioning, and through laboratory tests, computed tomography, body magnetic resonance imaging to exclude organic problems. In this circumstance, clinical observation revealed a deflection of mood tone reactive to the basic painful condition and current hospitalizations: the face appeared hypomimic, the speech was characterized by a feeble tone, the content of thought appeared coherent and contextual, although there was a recurring theme concerning the experience of the pain symptomatology and the consequent hospitalizations.
Anna's cognitive abilities were assessed with the WISC-IV (Weschler, 2003), which detected a disharmonious cognitive profile in which cognitive ability was pretty preserved $(\mathrm{IQ}=90)$, with vulnerabilities to solve novel abstract visual problems (Perceptual Reasoning Index) and manipulate verbal information in short-term memory (Working Memory Index). Regarding emotional abilities, the MASC (March et al., 1997) showed performance anxiety and separation panic. In addition, parents reported at the CBCL 618 internalizing problems with mainly somatic problems. Affective and anxiety problems were also found (CBCL 618 , Internalizing problems $\mathrm{T}=75$; Affective problems $\mathrm{T}$ =74; Anxiety problems T =73; Somatic problems T =83).

\section{Measures}

The Child Attachment Interview (CAI; ShmueliGoetz et al., 2008) is a semi-structured interview used to assess the child's attachment representations for both parents. The current CAI protocol contains 19 questions (CAI revised edition VIII; Shmueli-Goetz et al., 2008) and the CAI manual recommends that both video recordings and verbatim transcripts are used by coders in assigning ratings. The interview begins with a brief introduction in which the examiner explains to the child what he or she will be asked: 'This is an interview about you and your family. I will ask you some questions first about you and then about your relationship with your parents. For each question, I will ask you to give me some examples. This interview is not a test and there are no right or wrong answers. I just want you to tell me some things about you and your family from your point of view. The interview will last about half an hour, maybe a little longer'. The questions in the CAI tap the child's self-representation, representations of his/her primary caregivers, times of conflict, distress, illness, hurt, separation, and loss. Coders use eleven 9-point scales at dimensional level: Emotional Openness, Balance of Positive and Negative Reference to Attachment Figures, Use of Examples, Preoccupied Anger to mother/father, Idealization to mother/father, Dismissal to mother/father, Resolution of Conflicts, and Overall Coherence. A score between 1 and 9 is assigned to each of the scales, then placing children into one of four best-fitting attachment classifications at categorical level (secure, insecure-dismissing, insecure-preoccupied, disorganized) based on the distribution of the scale scores as well as on the consideration of the child's non-verbal behaviour. The Secure classification is indicated by relatively high (above 5 scores) Emotional Openness, Balance of Positive and Negative, Use of Examples, Resolution of Conflicts, and Overall Coherence as well as relatively low scores (below 5 score) on the Idealization, Dismissal, and Preoccupied Anger subscales. This is the opposite of insecurity. The CAI's psychometric properties have been demonstrated through a series of studies exploring its reliability and construct validity in both clinical and com- 
munity samples across multiple cultures (e.g., Bizzi et al., 2021b; Cavanna et al., 2018; Shmueli-Goetz et al., 2008; Venta et al., 2014a). Inter-rater reliability of the CAI scales has been reported to be good, with intraclass coefficients (ICCs) ranging from 0.58 to .98 (Bizzi et al., 2021b). Temporal stability of CAI was shown to be high over a 3-month period and adequate over 12 months (Shmueli-Goetz et al., 2008).

The Child and Adolescent Reflective Functioning Scale (CRFS; Ensink et al., 2013) is a measure of RF designed for youth and applied to CAI transcripts. The CRFS manual (Ensink et al., 2013) contains descriptions and examples of different levels and types of RF. Children's narratives are coded on an 11- point scale ( -1 to 9) focusing on the elaboration of interpersonal interactions and reactions in terms of mental state. The different levels of RF are: -1 : bizarre, disorganized response or avoided mentalization; 0 : absence of mentalization; 1 : self-description in terms of behaviour, non-mental characteristics; 2: descriptions without explicit reference to mental states; 3: some vague, basic but unelaborated references to mental states; 4: recognition that the experience of negative affect may elicit responses from others, which in turn can help to soothe or regulate the affect in various ways; 5: clear description of mental states showing a solid understanding; 6: clear but intentionally communicates of mental states; 7: understanding that different people may perceive a given behaviour or situation differently often based on differing knowledge of the situation or false belief; 8: unusually nuanced understanding of reactions of self and other that also incorporates a sense of feelings and reactions changing over time; 9: sophisticated mentalization capacity (Ensink et al., 2015).To obtain a general indicator of children's RF (CRF-G), the mean RF of all the coded responses we calculated. To obtain an indicator of self-focused RF (CRF-S), the mean RF for the four items eliciting self-descriptions and the child's reactions in response to upsetting events was used. Furthermore, an indicator of other-focused RF (CRF-O) was calculated based on the mean RF on the nine questions regarding the child's relationships with their parents and a description of parents' reactions when getting upset or when they argue. The CRFS' psychometric properties have been demonstrated by Ensink's studies (2004; 2015) and in the Italian context (Bizzi et al., 2021a). Inter-rater reliability of the CRFS items has been reported to be good, with intraclass coefficients (ICCs) ranging from .60 to 1.00 , with a median of .93 . Temporal stability of children's RF was shown to be high over a 3-month period and adequate over 12 months (Ensink, 2004).

The Psychodiagnostic Chart-2 (PDC-2; Gordon \& Bornstein, 2015) is an easy-to-use clinician report instrument, which is used for assessing patients according to the PDM-2 (Lingiardi \& McWilliams, 2017). Recently, a PDM-2 (0-18) version for children (4-11 ys) and adolescents (12-18 ys) has been developed (Lingiardi et al.,
2020) and several areas of functioning are considered: mental functioning (M-Axis), level of personality organization and personality patterns or disorders (P-Axis), manifest symptoms or concerns (S-Axis), and an additional area for other relevant considerations. For Mental Functions (M-Axis), a rating from Severe Deficits to Healthy (scores from 1 to 5) is used to indicate weaknesses and strengths. Regarding P-Axis, the Level of Personality Organization includes four dimensions: Identity, Object Relations, Level of Defenses, and Reality Testing. These dimensions are rated using a 10-point Likert scale (ranging from 1 - severe to 10 - healthy), while, for Personality Syndromes (only for adolescents), the PDC-2 documents as many personality syndromes as apply, together with the one or two most dominant personality styles. As a result, the PDC-2 gives a synthetic description of the different levels of the Overall Personality Organization in order to help the clinician with the assessment procedure. For Symptom Patterns (S-Axis), a clinician needs to indicate them on a scale from 1 to 5 (from severe to mild), together with their severity level. Finally, considerations on epigenetics, temperament, neuropsychology, attachment, cultural, and context aspects can be added. Studies on the PDC-2 showed good psychometric properties (Lingiardi \& Mc-Williams, 2017), including good convergent validity and very good 2-week retest reliability (0.92) of personality organization scale (Gazzillo et al., 2015).

\section{Procedure}

The study was approved by the Ethics Committee of the Gaslini Institute of Genoa Italy (rif. 216), according to the Declaration of Helsinki. Data was collected in the past year. Parents of these two patients were provided with a written document describing the procedures and purpose of the study; parents and their children provided informed consent and assent, respectively, and were informed that they could decline to participate in any part of the study. The assessment was conducted in a private room at the hospital by a psychologist who was trained in the administration of the CAI. The CRFS and the PDC-2 were subsequently coded from the CAI verbatim transcripts. For both instruments, coders were different from the clinician who administered the CAI interviews. Two clinical psychologists with extensive experience in using the CAI and CRFS, and trained directly by the measures' authors, coded the transcript separately, and discussed the rationale of their scores together until agreement was reached. A similar approach was used concerning the PDC-2. Three experienced female clinical psychologists, two of them with extensive knowledge in using the PDM, coded the transcripts with only the gender and age of the children known to them (see Table 1), then coded PDC-2 independently and discussed the scores assigned. Specifically, they started by sharing the rationale in relation to the overall scores, followed by a comparison of each aspect of the PDC-2 until agreement was reached. For both cases, scores 
were similar, with the maximum discrepancy of 1.5 . In case of disagreement, when the discussion did not result in consensus, raters read the transcripts together again, in order to find the information supporting their respective arguments and reach a new agreement. Because informa- tion collected through the CAI does not include information about children's symptomatology, data collected from the clinical assessments of the paediatric clinical centre Gaslini Institute of Genoa (Italy) have been used for the S-Axis.

Table 1. Psychodiagnostic Chart-2 Children and Adolescence Compilation.

\begin{tabular}{|c|c|c|c|c|}
\hline PDC-2 & CAI Questions & CAI Coding & CRFS & Other \\
\hline \multicolumn{5}{|l|}{ MC Axis: Mental Functioning } \\
\hline \multicolumn{5}{|l|}{ Cognitive and affective process } \\
\hline $\begin{array}{l}\text { Capacity for regulation, attention, } \\
\text { and learning }\end{array}$ & & Overall Coherence & & $\begin{array}{l}\text { Patient's attention behaviour during the } \\
\text { interview or explicit contents related to } \\
\text { school learning skills }\end{array}$ \\
\hline $\begin{array}{l}\text { Capacity for affective range, } \\
\text { communication, and understanding }\end{array}$ & $\begin{array}{l}\text { Self/Mum/Dad description } \\
\text { Mum/Dad angry }\end{array}$ & Emotional Openness & & \\
\hline $\begin{array}{l}\text { Capacity for mentalization and } \\
\text { reflective functioning }\end{array}$ & $\begin{array}{l}\text { Self/Mum/Dad description } \\
\text { Mum/Dad angry }\end{array}$ & & CFR-G & \\
\hline \multicolumn{5}{|l|}{ Identity and relationships } \\
\hline $\begin{array}{l}\text { Capacity for differentiation and } \\
\text { integration (identity) }\end{array}$ & Self-description & $\begin{array}{l}\text { Balance of Positive and } \\
\text { Negative Reference to } \\
\text { Attachment Figures }\end{array}$ & CRF-S & $\begin{array}{l}\text { CAI, as based on attachment representation, } \\
\text { focuses on the patients' relationship with } \\
\text { caregivers and more generally, on } \\
\text { attachment working models }\end{array}$ \\
\hline $\begin{array}{l}\text { Capacity for relationships and } \\
\text { intimacy }\end{array}$ & $\begin{array}{l}\text { Mum/Dad description } \\
\text { Parents love you? }\end{array}$ & $\begin{array}{l}\text { Dismissal } \\
\text { Idealization } \\
\text { Balance of Positive and } \\
\text { Negative Reference to } \\
\text { Attachment Figures }\end{array}$ & CRF-O & \\
\hline $\begin{array}{l}\text { Self-esteem regulation and } \\
\text { quality of internal experience }\end{array}$ & $\begin{array}{l}\text { Self/Mum/Dad descriptionill/ } \\
\text { get hurt/upset? }\end{array}$ & & CFR-S & \\
\hline \multicolumn{5}{|l|}{ Defense and coping } \\
\hline Impulse control and regulation & $\begin{array}{l}\text { Ill/get hurt/upset? } \\
\text { Parents far away? }\end{array}$ & & CFR-S & \\
\hline Defensive functioning: & $\begin{array}{l}\text { Dead? ill/get hurt/upset? } \\
\text { Hit or hurt? } \\
\text { Parents argue? }\end{array}$ & & & $\begin{array}{l}\text { The patient's verbal and nonverbal } \\
\text { reactions to CAI demanding questions }\end{array}$ \\
\hline $\begin{array}{l}\text { Adaptation, resilience, and } \\
\text { strength }\end{array}$ & $\begin{array}{l}\text { Mum/Dad angry? } \\
\text { Ill/get hurt/upset? } \\
\text { Hit or hurt? } \\
\text { Parents argue? }\end{array}$ & $\begin{array}{l}\text { Preoccupied Anger } \\
\text { Resolution of Conflicts }\end{array}$ & CRF-G & \\
\hline \multicolumn{5}{|l|}{ Self-awareness and self-direction } \\
\hline $\begin{array}{l}\text { Self-observing capacities } \\
\text { (psychological mindedness) }\end{array}$ & Mum/Dad angry & Overall Coherence & CRF-G & \\
\hline $\begin{array}{l}\text { Capacity to construct and use } \\
\text { internal standards and ideals }\end{array}$ & Mum/Dad angry & & & \\
\hline Meaning and purpose & Mum/dad like to bethree wishes & & CFR-S & \\
\hline \multicolumn{5}{|c|}{ PC-Axis: Level or personality organization } \\
\hline Identity & Self-description & & & \\
\hline Object Relations & Mum/Dad description & & & \\
\hline Level of defense & $\begin{array}{l}\text { Dead? } \\
\text { Ill/get hurt/upset? } \\
\text { Hit or hurt? } \\
\text { Parents argue? }\end{array}$ & & & $\begin{array}{l}\text { The patient's verbal and nonverbal } \\
\text { reactions to CAI demanding questions }\end{array}$ \\
\hline Reality Testing & & $\begin{array}{l}\text { Use of Example } \\
\text { Overall Coherence }\end{array}$ & & \\
\hline
\end{tabular}




\section{Results}

\section{Case 1 - Childhood: Luca}

Luca's CAI transcript allowed the evaluation of both the MC and the PC Axes of PDC-2. CAI, CRFS, and PDC-C scores were plotted to visualize the patient's functioning and were reported in Table 2.

Analyzing the CAI and CRFS scales, Luca showed abilities to describe his relational experience coherently and collaboratively providing relevant relational examples (CAI Use of Example: 6.5, Overall Coherence: 6.5). He was able to describe negative or conflictual events with little anger (CAI Preoccupied Anger: 1, Resolution of Conflicts: 6), without minimizing (CAI Dismissal: 1) or idealizing (CAI Idealization: 1) the importance of attachment figures and relationships, presenting them with balanced descriptions (CAI Balance of Positive and Negative Reference to Attachment Figures: 6). However, the ability to use a range of appropriate emotional terms (CAI Emotional Openness: 4.5), as well as the ability to identify one's mental states and those of others and understand the impact of his behaviour on others (CRF-G: 3.5) were more limited. He showed basic but unelaborated references to mental states, with major difficulties in recognizing one's own mental states (CRF-S: 2.5) compared to those of the other (CRF-O: 4).

Using a PDM-2 framework to deepen our understanding of Luca's functioning, the aforementioned vulnerabilities gleaned from the CAI were confirmed. The difficulties in emotional and attentional regulation, impulsivity, and learning were all detected, as well as the limited capacity for affective range and reflective functioning. During the interview, Luca described an interpersonal world characterized by parents and teachers constantly complaining about his school problems ('They tell me that I don't concentrate enough. I get distracted and I don't want to study. If I get yelled at, I still don't want to study'). Indeed, Luca seemed to learn only when very interested or engaged (PDC-C MC Capacity for regulation, attention, and learning: 3). Besides, he showed a limited ability to describe his feelings ('Last time that I fought with my dad, I felt ashamed because I was in front of my friends and second sad, nothing else') and, more generally, he struggled to access a full range of emotional expressions as expected for his chronological age (PDC$\mathrm{C} \mathrm{MC}$ Capacity for affective range, communication, and understanding: 3.5). A rigidity in recognizing others' emotions and taking others' perspectives emerged ('I don't remember, but I think she felt the same way'), with a basic capacity to identify personal affects and mental states lacking complexity and nuance (PDC-C MC Capacity for mentalization and reflective functioning: 3.5 ).

He reported having 'serene and protective' parental relationships and how important it was for him to still have them close in order to regulate his feelings ('I feel tense and my father calms me down to make me feel better and go to a safer field'). Without outside scaffolding, Luca did not understand his reactions, thus a moderate impairment of mental functioning was found (PDC-C MC Capacity for differentiation and integration - identity: 4). Despite his frequent outbursts and his difficulties in selfregulation, he was able to socialize with peers and used humor with them ('I make jokes at school and they all start to laugh. I like to cheer up my classmates'). Globally, the description of interpersonal relationships was positive and adequate but often disrupted by strong emotions such as anger or by stressors (PDC-C MC Impulse control and regulation: 2.5; PDC-C MC Adaptation, resilience, and strength: 3.5 ). In addition, the elaboration of others' representations appeared to be simplified and stereotypical (PDC-C MC Capacity for relationships and intimacy: 3). Similarly, his self-esteem appeared to be immature with a lack of complexity that diverts from the age-expected attainments for his age (PDC-C MC Self-esteem regulation and quality of internal experience: 3 ). Regarding defensive mechanisms, he used to act out more than what is expected at his age, minimizing or ignoring internal resources with repression and displacement mechanisms (PDC-C MC Defensive functioning: 3). Luca was found to recognize and invest in inner values (PDC-C MC Capacity to construct and use internal standards and ideals: 4) and seemed to be able to reflect on his experiences, though this capacity diminished when he experienced intense emotions (PDC-C MC Self-observing capacities psychological mindedness: 3.5 ). The overall MC-Axis score would place Luca's a moderate level of personality severity (Overall: Moderate impairments in mental functioning: 36.5$)$.

Globally, compared to normative development, Luca showed a stable even though immature and poor representation of the self (PDC-C PC Identity: 6) and others (PDC-C PC Object Relations: 6). Defenses were mainly of a neurotic type (PDC-C PC Level of defense: 6), while the reality testing seemed to be preserved (PDC-C PC Reality Testing: 8). In conclusion, he showed a neurotic Emerging Personality Organization (Mildly dysfunctional emerging personality patterns (Neurotic: 7). Taken together, the above suggested a neurotic personality functioning, characterized by an appropriate level of mental functioning with some specific areas of difficulty.

\section{Case 2 - Adolescence: Anna}

Anna's CAI transcript was analysed using both the MA and the PAAxes of the PDC-2. Anna's CAI, CRF and PDC-A scores were presented in Table 3.

Anna was considered to have formed a secure attachment bond to both parents, as determined by the CAI. She demonstrated a capacity to describe her relational experience coherently (CAI Overall Coherence: 6.5), expressing negative or conflictual events with little anger (CAI Preoccupied Anger: 1, Resolution of Conflict: 6) and with little or no minimizing (CAI Dismissal: 1). She clearly 
valued the importance of attachment figures and relationships, and whilst she was not able to recognize and integrate positive and negative aspects of parental figures (CAI Balance of Positive and Negative Reference to Attachment Figures: 2.5), she was not idealizing (CAI Idealization: 2.5). Anna clearly demonstrated a capacity to provide a range of emotional terms and make references to emotional states (CAI Emotional Openness: 6.5 ) as well as an ability to provide relevant and elaborated relational examples (CAI Use of Example: 6). In addition, the CRFS scales suggested that she was able to recognize the experience of negative affects that may elicit responses from others (CRF-G: 4), but her capacity to identify and describe her mental states (CRF-S: 3.5) was less developed and elaborate than her capacity to describe others' mental states (CRF-O: 4.5).
Analyzing Anna CAI's transcript using a PDM-2 framework, the above strengths and limitations were confirmed with further vulnerabilities identified. PDC-A was applied to Anna's CAI, in addition to, both the MA and the PA Axes of PDC-2.

During the interview, Anna was focused, but, when emotionally overstimulated, her attention and elaboration were hampered (PDC-A MA Capacity for regulation, attention, and learning: 3). She showed difficulties in describing and recognizing her and others' emotions ('I don't know how she felt, I think it's also normal'), with internal experiences rigidly compartmentalized and oversimplified. She showed a diminished capacity to express a wide range of emotional states either autonomously or with others as expected in adolescents. Furthermore, her narratives were characterized by intense anxiety hidden by the ex-

Table 2. Psychological assessment of Luca.

\begin{tabular}{ll}
\hline Measures & Results \\
\hline Child Attachment Interview (Shmueli-Goetz et al., 2008) & Emotional Openness $=4.5$ \\
& Balance $=6$ \\
& Use of Example $=6.5$ \\
& Anger to mother $=1$ \\
& Anger to father $=1$ \\
& Idealization to mother $=1$ \\
& Idealization to father $=1$ \\
& Dismissal to mother $=1$ \\
& Dismissal to father $=1$ \\
& Resolution of Conflict $=6$ \\
& Overall Coherence $=6.5$ \\
& Secure attachment to both parents \\
\hline Child Reflective Functioning Scale (Ensink et al., 2013) & General RF $=3.5$ \\
& Self-focused $\mathrm{RF}=2.5$ \\
& Other-focused $\mathrm{RF}=4$
\end{tabular}

Psychodiagnostic Chart-2 Children (Gordon \& Bornstein, 2015) MC-Axis: Mental Functioning

A. Cognitive and affective process

1. Capacity for regulation, attention, and learning: 3

2. Capacity for affective range, communication, and understanding: 3.5

3. Capacity for mentalization and reflective functioning: 3.5

B. Identity and relationships

4. Capacity for differentiation and integration (identity): 4

5. Capacity for relationships and intimacy: 3

6. Self-esteem regulation and quality of internal experience: 3

C. Defense and coping

7. Impulse control and regulation: 2.5

8. Defensive functioning: 3

9. Adaptation, resilience, and strength: 3.5

D. Self-awareness and self-direction

10. Self-observing capacities (psychological mindedness): 3.5

11. Capacity to construct and use internal standards and ideals: 4

Overall level of personality severity: 36.5 (moderate impairment of mental functioning)

PC-Axis: Level or personality organization

1. Identity: 6

2. Object Relations: 6

3. Level of defense: 6

4. Reality Testing: 8

Overall Personality Organization: 7 (neurotic)

SC-Axis: Symptom patterns

Oppositional-Provocative Disorder

Additional relevant considerations

History of impulsivity, disattention and behaviour problems, temperament vibrant and opposite, research greater centrality in the family 
pression of stereotypical positive emotions only (PDC-A MA Capacity for affective range, communication, and understanding: 2.5). Indeed, Anna was able to express and communicate emotions and to understand and reflect on her behaviour and reactions in terms of mental states only in a limited way (PDC-A MA Capacity for mentalization and reflective functioning: 2.5 ). During the interview, she described herself as shy ('I kept it all inside'), and still highly dependent on her parents ("Near my mom, I feel safe, so I give me security here. My father tries to motivate me and cheer me up') showing difficulties in identity development (PDC-A MA Capacity for differentiation and integration: 2 ). Her affective states were often character- ized by a high level of concern about illnesses, and her thoughts often focused on particular somatic symptoms. This influenced her relationships, which were characterized by an avoidance of new relationships with peers, resulting in social isolation (PDC-A MA Capacity for relationships and intimacy: 2; PDC-A MA Self-esteem regulation and quality of internal experience: 2 ) with excessive self-preoccupation, and her impulses remaining almost completely unexpressed (PDC-A MA Impulse control and regulation: 2.5). She used intellectualization ('I have a good relationship with my father because he gives me cues to read, we talk about important things happening in the world') and isolation of affect to manage

Table 3. Psychological assessment of Anna.

\begin{tabular}{ll}
\hline Measures & Results \\
\hline Child Attachment Interview (Shmueli-Goetz et al., 2008) & Emotional Openness $=6.5$ \\
& Balance $=2.5$ \\
& Use of Example $=6$ \\
& Anger to mother $=1$ \\
& Anger to father $=1$ \\
& Idealization to mother $=2.5$ \\
& Idealization to father $=2$ \\
& Dismissal to mother $=1$ \\
& Dismissal to father $=1$ \\
& Resolution of Conflict $=6$ \\
& Overall Coherence $=6.5$ \\
& Secure attachment to both parents \\
\hline Child Reflective Functioning Scale (Ensink et al., 2013) & General RF $=4$ \\
& Self-focused RF $=3.5$ \\
& Other-focused RF $=4.5$ \\
\hline
\end{tabular}

Psychodiagnostic Chart-2 Adolescents (Gordon \& Bornstein, 2015) MA-Axis: Mental functioning

A. Cognitive and affective process

1. Capacity for regulation, attention, and learning: 3

2. Capacity for affective range, communication, and understanding: 2.5

3. Capacity for mentalization and reflective functioning: 2.5

B. Identity and relationships

4. Capacity for differentiation and integration (identity): 2

5. Capacity for relationships and intimacy: 2

6. Self-esteem regulation and quality of internal experience: 2

C. Defense and coping

7. Impulse control and regulation: 2.5

8. Defensive functioning: 2.5

9. Adaptation, resilience, and strength: 1

D. Self-awareness and self-direction

10. Self-observing capacities (psychological mindedness): 2

11. Capacity to construct and use internal standards and ideals: 2

12. Meaning and purpose: 1.5

Overall level of personality severity: 25.5 (significant defects in basic mental functions)

PA-Axis: Level or personality organization

1. Identity: 3

2. Object Relations: 3

3. Level of defense: 4

4. Reality Testing: 4

Overall Personality Organization: 4 (borderline)

Personality Syndromes: Anxious-Avoidant: 2

Obsessive-Compulsive: 4

SA-Axis: Symptom patterns

Somatic Symptom Disorder

Additional relevant considerations

History of hospitalizations from the very first age, temperament inhibited and anxious, dependence on parental context 
anxiety (PDC-A MA Defensive functioning: 2.5 ), and it was clear that she was unable to manage complex socialemotional situations, showing more severe forms of symptomatology that compromise her personal and interpersonal functioning (PDC-A MA Adaptation, resilience, and strength: 1). Internal standards, values, and ideals were rigid (PDC-A MA Capacity to construct and use internal standards and ideals: 2). Anna was dependent from a parental point of view, poorly integrated in a realistic sense of one's capacities, without a direction or a sense of purpose (PDC-A MA Self-observing capacities: 2). Anna seemed trapped in the present and her difficulties did not enable her to think about future perspectives (PDC-A MA Meaning and purpose: 1.5).

The MA profile described a critical functioning representing globally a borderline level of personality severity, where Anna showed significant difficulties and limitations in most domains of mental functioning (Overall level of personality severity: Significant defects in basic mental functions: 25.5). Alongside these important limitations, problems in the organization and/or integration differentiation of self and objects (borderline organization) (PDC-A PA Identity: 3) were also suggested. Anna demonstrated a fear of losing control, including the wish to be in control of one's emotions and impulses, and the limited experiences of autonomy during development (PDC-A PA Object Relations: 3), as well as the use of defenses to manage anxiety as intellectualization, isolation of affect and overvaluing of thought versus feeling (PDCA PA Level of defense: 4). This functioning globally affected reality testing (PDC-A PA Reality Testing: 4). For these reasons, the PA Axis also referred to Anna's Personality Organization at a Borderline level (Overall Personality Organization: 4). In addition, the constellation of these scores suggested the presence of an Obsessive-Compulsive personality (PDC-A PA Personality Syndromes: Obsessive-Compulsive 4). A possible anxious or timid disposition, continuous preoccupation, and central affects as fear, anxiety, embarrassment also delineated AnxiousAvoidant personality (PDC-A PA Personality Syndromes: Anxious-Avoidant 2).

\section{Discussion}

Attachment and mentalization are critical predictors of social and emotional development in childhood and adolescence (Fonagy et al., 1991; Fonagy \& Luyten, 2016; Luyten \& Fonagy, 2018; Luyten et al., 2017, 2020). They are both associated with mental capacities such as affective regulation, defensive functioning, and resilience in both clinical and typical populations (Bowlby, 1969; Feldman, 2017; Fonagy et al., 2002; Lyons-Ruth et al., 1999, 2003; Long et al., 2020). The current study sought to establish the value of the combined use of CAI, CRFS, and PDC-2 in middle childhood and adolescence in capturing the depth of psychodynamic understanding of young patients, through the lens of attachment, mentalization, and socio-emotional development.

In the two cases discussed, coders were able to use the CAI transcript for scoring CAI and CRFS and completing all the $\mathrm{M}$ and $\mathrm{P}$ Axes of the PDC-2 (PDC-C and PDC-A). This suggests the great potential of the CAI protocol given that a single collection item permits the application of different measures, limiting the overloading of the patient in the assessment procedure. The combined use of CAI, CRFS, and PDC-2 not only provides a more comprehensive and sophisticated understanding of patient functioning, but also informs the clinical interventions. Indeed, analysing the clinical materials, the first case showed, through the CAI, the presence of emotional resources of Luca, such as his capacity to form strong bonds and the open communication of his inner world to others. At the same time, also some fragilities emerged, reflected in the limited use of emotional language, suggesting an immaturity of his affective expression, although it was grounded in balanced and coherent representations. The use of CRFS contributed more specific information about Luca's difficulties in the recognition of mental states, which were especially addressed to the self. PDC-C profile revealed a core regulation deficit influencing cognitive and interpersonal functioning. Taken together, these findings suggest that each measure adds several pieces of information about the emotional functioning of the patient, revealing a complex picture of both psychological strengths and vulnerabilities. The combined application of these assessment approaches capture a more nuanced picture of mental functioning that could inform intervention and treatment. Luca's ability to communicate emotions to a limited degree sits alongside emotion dysregulation, both of which would form the focus of treatment. On this line, mentalization-based treatment may be the useful intervention framework for Luca. This treatment is focused on helping children to affect regulation as a form of 'volume control'. Moreover, emotion regulation is grounded in the identification of the loss of mentalizing and replacing it with a more adaptive mode of thinking about self and others in a relational context (Midgley et al., 2017). The DSM-5 diagnosis he received (Oppositional-Provocative Disorder) can be better understood in light of his overall (neurotic) Personality Organization, indicating an age-appropriate sense of self and reality testing. This perspective reveals secure attachment representation as a resource that informs the complexity of Luca's profile.

In Anna's case, CAI scores suggested a global sense of secure representations however characterized by moderate idealization, though still demonstrating coherence. Anna's CRFS revealed poor mentalization ability, which was more pronounced with respect to the self. The PDCA underlined the vulnerability of the sense of self, in terms of identity, self-awareness, and self-direction. A rigid and idealistic representation of self and others was found that impacted on the possibility of creating an authentic con- 
tact with her inner world. As an adolescent, Anna took a step back in her developmental trajectory in terms of integration-differentiation of self and objects. Anna's PDCA profile integrated the severity of her psychopathological functioning and personality organization (Borderline level). Anna's case further highlights the strength in the combined application of these three measures to enhance understanding and inform treatment goals and planning. Indeed, although Anna's self/other representations were coherent, her idealization on the positive emerged as a core difficulty, restricting her inner and interpersonal functioning. In this direction, Anna's mental and personality functioning joined with the attachment representation revealed the risk of developing a deference behaviour. Deference describes a significant submission to others, in terms of assertions, skills and judgments. This behaviour plays a very important role in psychotherapy relationship, where the asymmetry between therapist and the adolescent can potentiate patient's deference (Locati et al., 2016, 2019). This specific behaviour might be dangerous for the stability of therapeutic alliance because an overlap with the patient's attachment representations obstruct the expression of discomfort during the sessions and to interrupt the therapy without any verbalization (Rennie, 1994). In light of this, Anne may benefit from a supportive psychotherapy where the most important goal is the need to open up the contact and the expression of negativity to arrive at a more truthful and integrated sense of self.

It is interesting to note that both Luca and Anna were securely attached patients and showed similar mentalization capacities reflected in basic but unelaborated references to mental states. However, the PDC-2 profiles described two mental and personality profiles that significantly diverge. This further suggests the complementarity of the measures used in this study revealing the importance of integrating categorical and dimensional analyses of CAI and CRFS with a systematic evaluation of the qualitative contents emerging from CAI transcripts. The application of the PDC-2 to CAI and CRFS allowed for the identification of specific psychological difficulties, namely, a dysregulated psychological functioning with respect to Luca, and a rigid and unauthentic psychological profile with respect to Anna, revealing important information for the treatment goals (Horowitz, 2018; Norcross $\&$ Wampold, 2011). In addition, the use of the PDC-2 differentiated for the developmental stage (childhood vs adolescence) in the presented cases allowed the interpretation of CAI protocol within a developmental perspective. In this light, Luca and Anna's cases suggest that moderate psychopathological severity may be observed in securely attached patients (Bastianoni et al., 2020; Bizzi et al., 2020). These findings add to the current debate suggesting that the relationship between attachment and developmental outcomes is complex and not always as strong as may be expected (Fearon et al., 2010; Groh et al., 2012; Madigan et al., 2016; Luyten et al., 2020). On the other hand,
CAI together with CFRS reveal patients' attachment representations and open up a more complex understanding of relational patterns and mentalization abilities grounded in these experiences. This perspective gives important clues on the relational functioning of the patients and the impact on the possible psychotherapy relationship and a more accurate choice of treatment planning.

\section{Conclusions}

The CAI is a sensitive and intense task that provides important information about assessment and treatment indications for children and adolescence. The use of mental states language within this narrative may be considered a fundamental indicator of ongoing reflecting processes and is clinically informative (Bastianoni et al., 2021; Bohanek \& Fivush, 2010). Based on the preliminary results of the current study, this rich material seems useful not only for assessing attachment and mentalization specifically or exclusively, but also to describe global mental functioning and personality organization of children and adolescents. Indeed, the present study provides preliminary evidence of the applicability of the PDM-2 framework, through the PDC-2, on CAI transcript, providing an effective and comprehensive approach to children and adolescents assessment.

The use of combined measures is widely recognized as the preferable approach to understanding the uniqueness of a person, as no one psychological measure can be considered exhaustive in understanding people's psychological functioning (Hopwood \& Bornstein, 2014; Malberg et al., 2017). The multimethod assessment approach reflects how each contributes uniquely to the whole, allowing for a more complex and sophisticated understanding of young patients.

Despite the promise in adopting the aforementioned multi-method approach, several limitations are of note. Firstly, the study involved a careful analysis of only two cases and thus a larger study is imperative, building on this preliminary work. Moreover, with respect to both cases, a secure attachment classification was considered on the CAI.

Future research may improve the joint application of the three measures in order to reveal the interaction between attachment representation and mentalization in different mental and personality patients functioning. More studies may test the CAI's contribution to coding PDC-C and PDC-A with school-aged children drawn from a range of clinical samples and with a range of attachment representations. Finally, it would be interesting to investigate the application of CAI, CRFS, and PDC-2 to children and adolescent patients with the specific aim of tailoring or establishing treatment outcomes. Using the three assessment tools, namely, the CAI, CRFS, and PDC-2, in combination as psychodiagnostic tools, for a pre-treatment and pre-post testing may be a fruitful way forward. 


\section{References}

Achenbach, T., \& Rescorla, L. (2001). Manual for the ASEBA school age forms \& profiles. Burlington: University of Vermont Research Center for Children Youth \& Families.

Ainsworth, M. D. S., Blehar, M. C., Waters, E., \& Wall, S. (1978). Patterns of attachment: A psychological study of the Strange Situation. Mahwah: Lawrence Erlbaum.

Baron-Cohen, S., Wheelwright, S., Hill, J., Raste, Y., \& Plumb, I. (2001). The 'Reading the Mind in the Eyes' Test revised version: a study with normal adults, and adults with Asperger syndrome or high-functioning autism. The Journal of Child Psychology and Psychiatry and Allied Disciplines, 42(2), 241-251. doi:10.1017/S0021963001006643.

Bastianoni, C., Mora, S. C., De Gregorio, E., \& Bizzi, F. (2020). Exploring adopted adolescents' inner world through the lens of qualitative methodology. Children and Youth Services Review, 113, 104973. doi:10.1016/j.childyouth.2020.104973.

Bastianoni, C., Charpentier-Mora, S., Cavanna, D., \& Bizzi, F. (2021). Adopted Adolescents Talk about the Mental States: a Qualitative Exploratory Study. Mediterranean Journal of Clinical Psychology, 9(2). doi:10.13129/2282-1619/mjcp-2956.

Bizzi, F. (2019). The quality of attachment in children with somatic symptom disorders and related disorders. Psicologia Clinica Dello Sviluppo, 23(1), 139-151. doi:10.1449/93137.

Bizzi, F., Cavanna, D., Castellano, R., \& Pace, C. S. (2015). Children's mental representations with respect to caregivers and post-traumatic symptomatology in somatic symptom disorders and disruptive behaviour disorders. Frontiers Psychology, 6, 1125. doi:10.3389/fpsyg.2015.01125.

Bizzi, F., Charpentier-Mora, S., Cavanna, D., Borelli, J. L., \& Ensink, K. (2021a). Testing Children's Mentalizing in Middle Childhood: Adopting the Child and Adolescent Reflective Functioning Scale with Clinical and Community Children. Journal of Child and Family Studies, 1-14. doi:10.1007/s10826-021-02057-4.

Bizzi, F., Ensink, K., Borelli, J. L., Mora, S. C., \& Cavanna, D. (2019). Attachment and reflective functioning in children with somatic symptom disorders and disruptive behaviour disorders. European Child \& Adolescent Psychiatry, 28(5), 705-717. doi:10.1007/s00787-018-1238-5.

Bizzi, F., Shmueli-Goetz, Y., Castellano, R., \& Cavanna, D. (2018). A multi-assessment approach to attachment in middle childhood and early adolescence in two clinical groups. Testing, Psychometrics, Methodology in Applied Psychology, 25(3), 409-427. doi:10.4473/TPM25.3.6.

Bizzi, F., Shmueli-Goetz, Y., Castellano, R., San Martini, P., \& Cavanna, D. (2021b). Psychometric Properties of the Child Attachment Interview in Italian Context: A Focus on Normative and Specific Clinical Groups in School-Aged Children. Psychological Reports, 124(1), 382-410. doi:10.1177/ 0033294120905515.

Bohanek, J. G., \& Fivush, R. (2010). Personal narratives, wellbeing, and gender in adolescence. Cognitive Development, 25(4), 368-379. doi:10.1016/j.cogdev.2010.08.003.

Borelli, J. L., David, D. H., Crowley, M. J., \& Mayes, L. C. (2010). Links between disorganized attachment classification and clinical symptoms in school-aged children. Journal of Child and Families Study, 19, 243-256. doi:10.1007/ s10826-009-9292-8.

Bosmans, G., \& Kerns, K. A. (2015). Attachment in middle childhood: Progress and prospects (Special issue: Attach- ment in middle childhood: Theoretical advances and new directions in an emerging field). New Directions for Child and Adolescent Development, 148, 1-14. doi:10.1002/ cad. 20100

Bowlby, J. (1969). Attachment and loss: Volume I Attachment. New York: Basic Books.

Bowlby, J. (1980). Attachment and loss: Volume III: Loss, sadness and depression. New York: Basic Books.

Bretherton, I. (1985). Attachment theory: Retrospect and prospect. Monographs of the society for research in child development, 3-35.

Carr, A. (2017). Social and emotional development in middle childhood. In D. Skuse, H. Bruce \& L. Dowdney (Eds.), Child psychology and psychiatry: frameworks for clinical training and practice. 3rd ed. (pp. 83-90). London: Blackwell.

Cavanna, D., Bizzi, F., San Martini, P., \& Castellano, R. (2018). Child Attachment Interview: A psychometric study of an Italian sample. Psicologia Clinica Dello Sviluppo, 22, 115142. doi:10.1449/89588.

Corman, L. (1964). The Family Drawing Test in Medical-Pedagogical Practice. Paris: P.U.F. Paris.

Costa-Cordella S, Luyten P, Giraudo F, Mena F, Shmueli-Goetz Y, \& Fonagy P. (2020). Attachment and stress in children with type 1 Diabetes and their mothers. Revista Chilena de Pediatria, 91(1), 68-75. doi:10.32641/rchped.v91i1.1197.

Crowell, J. A., Treboux, D., Gao, Y., Fyffe, C., Pan, H., \& Waters, E. (2002). Assessing secure base behaviour in adulthood: Development of a measure, links to adult attachment representations and relations to couples' communication and reports of relationships. Developmental Psychology, 38(5), 679-693. doi:10.1037/0012-1649.38.5.679.

Emde, R. N., Wolf, D. P., \& Oppenheim, D. (Eds.). (2003). Revealing the inner worlds of young children: The MacArthur Story Stem Battery and parent-child narratives. New York: Oxford University Press.

Ensink, K. (2004). Assessing theory of mind, affective understanding and reflective functioning in primary school-aged children. London: University College London. Unpublished $\mathrm{PhD}$ Dissertation.

Ensink, K., Bégin, M., Normandin, L., \& Fonagy, P. (2016). Maternal and child reflective functioning in the context of child sexual abuse: pathways to depression and externalising difficulties. European Journal of Psychotraumatology, 7, 30611 doi:10.3402/ejpt.v7.30611.

Ensink, K., Bégin, M., Normandin, L., Godbout, N., \& Fonagy, P. (2017). Mentalization and dissociation in the context of trauma: Implications for child psychopathology. Journal of Trauma Dissociation, 18, 11-30. doi:10.1080/ 15299732. 2016.1172536.

Ensink, K., Normandin, L., Target, M., Fonagy, P., Sabourin, S., $\&$ Berthelot, N. (2015). Mentalization in children and mothers in the context of trauma: an initial study of the validity of the Child Reflective Functioning Scale. British Journal of Developmental Psychology, 33(2), 203-217. doi:10.1111/bjdp.12074.

Ensink, K, Target, M. \& Oandasan, C. (2013). Child reflective functioning scale scoring manual: for application to the Child Attachment Interview. London: Anna Freud Centre University College London. [Unpublished manuscript].

Fearon, R. P., Bakermans-Kranenburg, M. J., Van IJzendoorn, M. H., Lapsley, A. M., \& Roisman, G. I. (2010). The significance of insecure attachment and disorganization in the development of children's externalizing behaviour: a 
meta-analytic study. Child Development, 81(2), 435-456. doi:10.1111/j.1467-8624.2009.01405.x.

Feldman, R. (2017). The neurobiology of human attachments. Trends in Cognitive Science, 21, 80-99. doi:10.1016/j.tics. 2016.11.007.

Fonagy, P., Gergely, G., Jurist, E., \& Target, M. (2002). Affect regulation, mentalization, and the development of the self. New York: Other Press.

Fonagy, P., Gergely, G., \& Target, M. (2007). The parent-infant dyad and the construction of the subjective self. Journal of Child Psychology and Psychiatry, 48(3-4), 288-328. doi:10.1111/j.1469-7610.2007.01727.xPMID: 17355400.

Fonagy, P., \& Luyten, P. (2016). A multilevel perspective on the development of borderline personality disorder. In D. Cicchetti (Ed.), Developmental psychopathology: Maladaptation and psychopathology (pp. 726-792). New Jersey: John Wiley \& Sons. doi:10.1002/9781119125556.devpsy317.

Fonagy, P., Steele, M., Moran, G., Steele, H., \& Higgitt, A. (1991). Measuring the ghost in the nursery: a summary of the main findings of the Anna Freud Centre-University College, London Parent-Child Study. Bulletin of the Anna Freud Centre, 14(2), 115-131. doi:10.1177/000306519304100403.

Fonagy, P., \& Target, M. (1997). Attachment and reflective function: their role in self-organization. Development and Psychopathology, 9(4), 679-700. doi:10.1017/ S0954579497001399.

Fonagy, P., \& Target, M. (2006). The mentalization-focused approach to self-pathology. Journal of Personality Disorders, 20(6), 544-576. doi:10.1521/pedi.2006.20.6.544.

Gazzillo, F., Lingiardi, V., Del Corno, F., Genova, F., Bornstein, R. F., Gordon, R. M., \& McWilliams, N. (2015). Clinicians' emotional responses and Psychodynamic Diagnostic Manual adult personality disorders: A clinically relevant empirical investigation. Psychotherapy, 52, 238-246. doi:10.1037/ a0038799.

George, C., Kaplan, N., \& Main, M. (1985). Adult Attachment Interview. Berkeley: University of California. [Unpublished manuscript].

Glazebrook, K., Townsend, E., \& Sayal, K. (2015). The role of attachment style in predicting repetition of adolescent selfharm: A longitudinal study. Suicide Life Threatening Behavior, 45, 664-678. doi:10.1111/sltb.12159.

Gordon, R. M., \& Bornstein, R. F. (2015). The Psychodiagnostic Chart-2 (PDC-2) v. 8.1. doi:10.13140/RG.2.1.4022.1206.

Gordon, R. M., \& Bornstein, R. F. (2018). Construct validity of the psychodiagnostic chart: A transdiagnostic measure of personality organization, personality syndromes, mental functioning, and symptomatology. Psychoanalytic Psychology, 35, 280-288. doi:10.1037/pap0000142.

Groh, A. M., Roisman, G. I., van IJzendoorn, M. H., BakermansKranenburg, M. J., \& Fearon, R. P. (2012). The significance of insecure and disorganized attachment for children's internalizing symptoms: A meta-analytic study. Child Development, $83(2), \quad 591-610$. doi:10.1111/j.1467-8624.2011.01711.x.

Hart, J. R., Venta, A., \& Sharp, C. (2017). Attachment and thought problems in an adolescent inpatient sample: The mediational role of theory of mind. Comprehensive Psychiatry, 78, 38-47. doi:10.1016/j.comppsych.2017.07.002.

Holland, S., Dallos, R., \& Olver, L. (2012). An exploration of young women's experiences of living with excess weight. Clinical Child Psychology and Psychiatry, 17, 538-552. doi:10.1177/1359104511426411.
Hopwood, C. J., \& Bornstein, R. F. (Eds.). (2014). Multimethod clinical assessment. New York: Guilford Publications.

Horowitz, M. J. (2018). Formulation as a basis for planning psychotherapy treatment. Washington, DC: American Psychiatric Publishing.

Jardin, C., Venta, A., Newlin, E., Ibarra, S., \& Sharp, C. (2017). Secure attachment moderates the relation of sexual trauma with trauma symptoms among adolescents from an inpatient psychiatric facility. Journal of Interpersonal Violence, 32(10), 1565-1585. doi:10.1177/0886260515589928.

Jewell, T., Gardner, T., Susi, K., Watchorn, K., Coopey, E., Simic, M., Fonagy, P., \& Eisler, I. (2019). Attachment measures in middle childhood and adolescence: A systematic review of measurement properties. Clinical Psychology Review, 68, 71-82. doi:10.1016/j.cpr.2018.12.004.

Kasen, S., Cohen, P., Skodol, A. E., First, M. B., Johnson, J. G., Brook, J. S. \& Oldham, J. M. (2007), Comorbid personality disorder and treatment use in a community sample of youths: a 20-year follow-up. Acta Psychiatrica Scandinavica, 115, 56-65. doi:10.1111/j.1600-0447.2006.00842.x.

Kernberg, O. F. (2018). Commentary on the Psychodynamic Diagnostic Manual, 2nd Edition: What does the PDM-2 add to the current diagnostic panorama? Psychoanalytic Psychology, 35, 294-295. doi:10.1037/pap0000208.

Klagsbrun, M., \& Bowlby, J. (1976). Responses to separation from parents: A clinical test for young children. British Journal of Projective Psychology \& Personality Study, 21(2), 7-27.

Lingiardi, V., \& McWilliams, N. (Eds.). (2017). Psychodynamic Diagnostic Manual (2nd ed.). New York: Guilford Press.

Lingiardi, V., \& McWilliams, N. (2018). Introduction to the Special Issue on the Psychodynamic Diagnostic Manual, 2nd Edition (PDM-2): The PDM: Yesterday, today, tomorrow. Psychoanalytic Psychology, 35, 289-293. doi:10.1037/ pap0000188.

Lingiardi, V., McWilliams N., \& Speranza A.M. (2020). Manuale Diagnostico Psicodinamico PDM-2: 0/18, Infanzia e Adolescenza. Milano: Raffaello Cortina.

Locati, F., De Carli, P., Lang, M., \& Parolin, L. (2019). The flip side of collaborative alliance: a single-case study. Research in Psychotherapy: Psychopathology, Process, and Outcome, 22(2), 384. doi:10.4081/ripppo.2019.384.

Locati, F., De Carli, P., Tarasconi, E., Lang, M., \& Parolin, L. (2016). Beyond the mask of deference: exploring the relationship between ruptures and transference in a single-case study. Research in Psychotherapy: Psychopathology, Process and Outcome, 19(2). doi:10.4081/rippo.2016.212.

Long, M., Verbeke, W., Ein-Dor, T., \& Vrtička, P. (2020). A functional neuro-anatomical model of human attachment (NAMA): Insights from first-and second-person social neuroscience. Cortex, 126, 281-321. doi:10.1016/j. cortex.2020.01.010.

Luborsky, L., \& Crits-Christoph, P. (1990). Understanding transference: The CCRT method. New York: Basic Books.

Luyten, P., Campbell, C., Allison, E., \& Fonagy, P. (2020). The mentalizing approach to psychopathology: State of the art and future directions. Annual Review of Clinical Psychology, 16, 297-325. doi:10.1146/annurev-clinpsy-071919015355.

Luyten, P., \& Fonagy, P. (2018). The stress-reward-mentalizing model of depression: An integrative developmental cascade approach to child and adolescent depressive disorder based on the Research Domain Criteria (RDoC) approach. Clinical 
Psychology Review, 64, 87-98. doi:10.1016/j.cpr.2017. 09.008 .

Luyten, P., Mayes, L. C., Nijssens, L., \& Fonagy, P. (2017). The parental reflective functioning questionnaire: Development and preliminary validation. PLoS One, 12(5), e 0176218. doi:10.1371/journal.pone.0176218.

Lyons-Ruth, K., Bronfman, E., \& Parsons, E. (1999). Atypical attachment in infancy and early childhood among children at developmental risk. IV. Maternal frightened, frightening, or atypical behaviour and disorganized infant attachment patterns. Monographs of the Society for Research in Child Development, 64(3), 67-96. doi:10.1111/1540-5834.00034.

Lyons-Ruth, K., Yellin, C., Melnick, S., \& Atwood, G. (2003). Childhood experience of trauma and loss have different relations ot maternal unresolved and Hostile-Helpless states of mind on the AAI. Attachment and Human Development, 5(4), 330-352. doi:10.1080/14616730310001633410.

Madigan, S., Brumariu, L. E., Villani, V., Atkinson, L., \& LyonsRuth, K. (2016). Representational and questionnaire measures of attachment: A meta-analysis of relations to child internalizing and externalizing problems. Psychological Bulletin, 142(4), 367-399. doi:10.1037/bul0000029.

Malberg, N., Rosenberg, L., \& Malone, J. C. (2017). Emerging personality patterns and difficulties in childhood. Psychodynamic Diagnostic Manual, Second Edition: PDM-2, 501539. doi:10.1002/wps.20233.

Malone, J. C., Piacentini, E., \& Speranza, M. (2018). Reclaiming the developmental lens for adolescent formulation and diagnosis: Application of the PDM-2 to clinical cases. Psychoanalytic Psychology, 35(3), 339. doi:10.1037/ pap0000194.

March, J.S., Parker, J.D., Sullivan, K., Stallings, P., \& Conners, C.K. (1997). The Multidimensional Anxiety Scale for Children (MASC): factor structure, reliability, and validity. Journal of the American Academy of Child and Adolescent Psychiatry, 36(4), 554-65. doi:10.1097/00004583-199704000-00019.

Midgley, N., Ensink, K., Lindqvist, K., Malberg, N., \& Muller, N. (2017). Mentalization-based treatment for children: $A$ time-limited approach. Washington, D.C.: American Psychological Association.

Norcross, J.C., \& Wampold, B.E. (2011). Evidence-based therapy relationships: research conclusions and clinical practices. Psychotherapy. 48(1), 98-102. doi:10.1037/a0022161.

Patriarca, E., Brusadelli, E., \& Grenyer, B. F. S. (2020). A Bridge Between Person-Based Versus Symptom-Based Nosology: A Clinical Case Study Using the Psychodiagnostic Chart-2. Psychoanalytic Psychology. doi:10.1037/pap0000308.

Privizzini, A. (2017). The child attachment interview: A narrative review. Frontiers in Psychology, 8, 384. doi:10.3389/ fpsyg.2017.00384.

Rasmussen, P. D., Bilenberg, N., Shmueli-Goetz, Y., Simonsen, E., Bojesen, A. B., \& Storebø, O. J. (2019). Attachment representations in mothers and their children diagnosed with ADHD: Distribution, transmission, and impact on treatment outcome. Journal of Child and Family Studies, 28, 10181028. doi:10.1007/s10826-019-01344-5.

Rennie, D.L. (1994). Clients deference in psychotherapy. Journal of Counseling Psychology, 41, 427-437.

Salcuni, S., Di Riso, D., \& Lis, A. (2014). 'A child's nightmare.
Mum comes and comforts her child.' Attachment evaluation as a guide in the assessment and treatment in a clinical case study. Frontiers in Psychology, 5, 912. doi:10.3389/fpsyg. 2014.00912.

Shai, D., \& Belsky, J. (2017). Parental embodied mentalizing: How the nonverbal dance between parents and infants predicts children's socio-emotional functioning. Attachment \& Human Development, 19(2), 191-219. doi:10.1080/ 14616734.2016.1255653.

Sharp, C., \& Rossouw, T. (2019). Borderline personality pathology in adolescence. Handbook of mentalizing in mental health practice, 281-300. Berlin: Karger Publishers.

Shmueli-Goetz, Y., Target, M., Fonagy, P., \& Datta, A. (2008). The Child Attachment Interview: A psychometric study of reliability and discriminant validity. Developmental Psychology, 44, 939-956. doi:10.1037/0012-1649.44 .4.939.

Steele, H., \& Steele, M. (2005). The Construct of Coherence as an Indicator of Attachment Security in Middle Childhood: The Friends and Family Interview. In K. A. Kerns \& R. A. Richardson (Eds.), Attachment in middle childhood (pp. 137-160). New York: The Guilford Press.

Sroufe, L. A. (1990). Considering normal and abnormal together: The essence of developmental psychopathology. Development and Psychopathology, 2(4), 335-347.

Tanzilli, A., Di Giuseppe, M., Giovanardi, G., Boldrini, T., Caviglia, G., Conversano, C., \& Lingiardi, V. (2021). Mentalization, attachment, and defense mechanisms: a Psychodynamic Diagnostic Manual-2-oriented empirical investigation. Research in Psychotherapy: Psychopathology, Process, and Outcome, 24(1). doi:10.4081/ripppo.2021.531.

Tessier, V. P., Normandin, L., Ensink, K., \& Fonagy, P. (2016). Fact or fiction? A longitudinal study of play and the development of reflective functioning. Bulletin of the Menninger Clinic, 80(1), 60-79. doi:10.1521/bumc.2016.80.1.60.

Vanwoerden, S., Greiner, I., Ensink, K., \& Sharp, C. (2019). The relations between self-and caregiver-focused reflective function and theory of mind in the context of borderline pathology in adolescence. Psychiatry Research, 273, 274-280. doi:10.1016/j.psychres.2019.01.042.

Venta, A., Shmueli-Goetz, Y., \& Sharp, C. (2014a). Assessing attachment in adolescence: A psychometric study of the Child Attachment Interview. Psychological Assessment, 26, 238-255. doi:10.1037/a0034712.

Venta, A., \& Sharp, C. (2014b). Attachment organization in suicide prevention research preliminary findings and future directions in a sample of inpatient adolescents. Crisis, 35, 60-66. doi:10.1027/0227-5910/a000231.

Vrouva, I. \& Fonagy, P. (2009). Development of the Mentalizing Stories for Adolescents (MSA). Journal of the American Psychoanalytic Association, 57, 1174-1179.

Vrouva, I., Target, M., \& Ensink, K. (2012). Measuring mentalization in children and young people. In N. Midgley \& I. Vrouva (Eds.), Minding the child: Mentalization-based interventions with children, young people and their families (pp. 54-76). London: Routledge/Taylor \& Francis Group.

Wechsler, D. (2003). Wechsler intelligence scale for childrenFourth edition (WISC-IV). San Antonio, TX: The Psychological Corporation. 